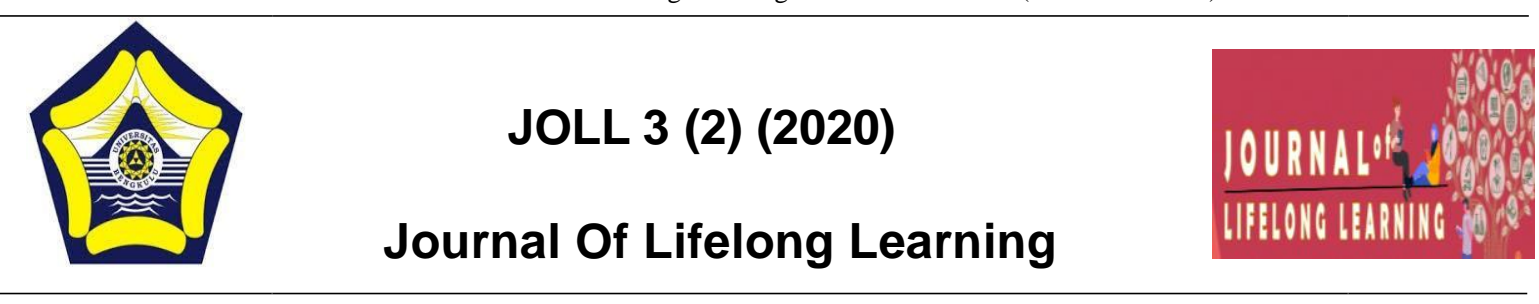

\title{
PELAKSANAAN STADANR OPERASIONAL PROSEDUR (SOP) POLA ASUH PADA ANAK BALITA DI PANTI ASUHAN KASIH SAYANG KOTA BENGKULU
}

\author{
Putri Darmalena', Rufran Zulkarnain² ${ }^{2}$, Sofino3 \\ ${ }^{1}$ Putri Darmalena, Universitas Bengkulu, Indonesia, putridarmelena2415@gmail.com \\ ${ }^{2}$ Rufran Zulkarnain, Universitas Bengkulu, Indonesia, rufran@unib.ac.id \\ 3 Sofino, Universitas Bengkulu, Indonesia, sofino@unib.ac.id
}

\begin{abstract}
The purpose of this study was to find out and describe in detail the SOP for children under five at the Kasih Sayang Orphanage, Bengkulu City. This research is a descriptive qualitative research. This study uses interview data collection techniques, observation and documentation. The research subjects were Merlin Darlia as the orphanage educator, Riko Tampati as the head of the orphanage and Fera Isnata as the supervisor. Checking the validity of the data used time triangulation, subject triangulation and technical triangulation. The results obtained were the implementation of standard operating procedures for intake of children under five, refreshing activities, sleep schedules, learning activities and prayer schedules. This orphanage has 45 foster children consisting of 7 toddlers 3 babies and 35 teenagers.
\end{abstract}

Keywords: SOP, orphanage

\section{$\square$ Addresscorrespondence:}

Jl.W.R.Supratman,KandangLimun,MuaraBangkaHulu,

KotaBengkulu,Bengkulu38371 


\section{PENDAHULUAN}

Menurut Goerge R. Terry (1986) menjelaskan bahwa, Pelaksanaan merupakan usaha menggerakan anggota kelompok sedemikian rupa hingga mereka berkeinginan dan berusaha untuk mencapai sasaran perusahaan dan sasaran anggota perusahan. Dapat disimpulkan bahwa, Pelaksanaan adalah upaya untuk menjalankan suatu rencana yang telah direncanakan dan dilaksanakan dengan sungguh-sungguh agar kegiatan dapat berjalan sesuai tujuan yang telah ditetapkan.

Menurut Hartika dalam Insani, $(2010,1)$. SOP atau standar operasional prosedur adalah dokumen yang berisi serangkaian instruksi tertulis yang dibakukan mengenai berbagai proses penyelenggaraan administrasi perkantoran yang berisi cara melakukan pekerjaan, waktu pelaksanaan, tempat penyelenggraan dan aktor yang berperan dalam kegiatan.

Menurut Indah Puji, 2014:30:

Tujuan pembuatan SOP adalah untuk menjelaskan perincian atau standar yang tetap mengenai aktivitas pekerjaan yang berulang-ulang yang diselenggarakan dalam suatu organisasi.

Dapat disimpulkan bahwa tujuan dan fungsi SOP (Standar Operasional Prosedur) tujuan SOP adalah sebagai acuan agar dapat mempermudah setiap proses kerja dan meminimalisir adanya kesalahan di dalam proses pengerjaan, sedangkan fungsi SOP adalah sebagai pedoman dalam melaksanakan pekerjaan agar dapat memperlancar tugas.
Menurut Depsos RI, 2004. Panti sosial asuhan adalah suatu lembaga usaha kesejahteraan sosial pada anak terlantar dengan memberikan pelayanan pengganti orang tua atau keluarga untuk anak yang bertanggung jawab dalam memenuhi kebutuhan fisik, mental, dan sosial kepada anak asuh serta memberikan kesempatan yang luas untuk pengembangan kepribadiannya sesuai dengan yang diharapkan sebagai bagian dari generasi penerus cita-cita bangsa dan berkembang secara wajar.

Dapat disimpulkan panti asuhan adalah memberikan pelayanan kesejahteraan sosial kepada anak yang terlantar serta memberikan pelayanan sebagai pengganti orang tua atau keluarga dan bertanggung jawab dengan memenuhi kebutuhan fisik, mental dan sosial kepada anak asuh.

Menurut Santrock, John W. 2017, Pengelompokkan Anak Balita:

a. Prenatal-pembuahan sampai kelahiran

b. Masa bayi-dari lahir sampai 18-24 bulan

c. Masa kanak-kanak awal-akhir masa bayi sampai sekitar 5-6 tahun

d. Masa kanak-kanak menengah dan akhir-sekitar 6-11 tahun

e. Remaja-dimulai dari 10-12 tahun dan berakhir pada 18-22 tahun.

Berdasarkan data dari Dinas Sosial Provinsi Bengkulu panti asuhan yang ada di kota bengkulu yaitu, Panti Asuhan Payung Yatim, Panti Asuhan Kasih Sayang Bengkulu, Panti Asuhan Bumi Raflesia, Panti Asuhan Al-marhamah, Panti Asuhan Bintang Terampil Bengkulu, Panti Asuhan Zam-zam 
Global, Panti Asuhan bunga Harapan, Panti Asuhan Payung Yatim (PAPY), Panti Asuhan Tunas Harapan Jitra, Panti Asuhan Mutiara Kasih Yayasan kinal Amanah, Panti Asuhan Yayasan Swasta Mandiri, Panti Salam Yayasan Sultan Bengkulu, LKSA Asrama Yatim Al-Fida, Panti Asuhan Titipan Suci Adam dan Hawa (data terlampir).

Pada Tahun 2020 Panti Asuhan Kasih Sayang Kota Bengkulu ini memiliki 45 anak asuh yang terdiri diantaranya 7 balita 3 bayi dan 35 anak remaja dan didirikan oleh ibu Merlin Darlia dan Bapak Riko Tampati, serta 3 anggota sekretariatan. Ada pun pola asuh yang diterapkan di panti asuhan kasih sayang kota bengkulu yaitu menggunakan parentting kasih sayang dimana pengasuh memiliki keterkaitan emosional pada anak untuk mengetahui sikap dan tanggap anak, pola asuh kasih sayang ini biasanya digunakan untuk menghindari hukuman fisik dan mengajarkan anak untuk disiplin melalui interaksi antara pengasuh dan balita. Standar Operasional Prosedur (SOP) pada panti Asuhan Kasih Sayang Kota Bengkulu.

\section{METODE}

Penelitian ini merupakan jenis penelitian kualitatif yang bersifat deskriptif. Sugiyono (2016:9), mengemukakan bahwa metode penelitian kualitatif adalah metode penelitian yang digunakan untuk meneliti pada kondisi obyek yang alamiah dimana peneliti adalah sebagai instrumen kunci. Oleh karena itu, penelitian ini dilakukan secara kualitatif yang bertujuan untuk mendeskripsikan secara rinci dan mendalam mengenai SOP di Panti Asuhan Kasih Sayang Kota Bengkulu.

Adapun deskripsi informan penelitian atau subjek penelitian yaitu:
1. Ibu Merlin Darlian selaku pendiri Panti

2. Bapak Riko Tampati sealaku ketua panti

3. Ibu Fera Isnata selaku pengasuh anak balita

Subjek pada penelitian ini telah dipilih dan ditetapkan oleh peneliti, sesuai dengan data dan informasi yang diperlukan dan subjek dianggap menguasai tujuan penelitian ini untuk menjawab permasalahan yang telah dirumuskan. Penelitian dilaksanakan dengan memfokuskan beberapa pertanyaan penting merujuk pada rumusan masalah yang diajukan kepada partisipan.

Penelitian ini dilakukan dalam waktu 2 minggu yaitu dimulai dari tanggal 27 Januarisampai dengan 09 Februari 2021. Tempat dilaksanakannya penelitian secara umum adalah di Panti Asuhan Kasih Sayang Kota Bengkulu. Pelaksanaan penelitian ini bertujuan untuk membuktikan dan mendeskripsikan SOP pada anak balita yakni asupan pada anak balita, jadwal tidur dan jadwal ibadah.

Teknik pengumpulan data yang digunakan secara umum yaitu menggunakan:

1. Teknik Wawancara.

Menurut Sugiyono, $(2006: 262)$ wawancara terstruktur digunakan sebagai teknik pengumpulan data, bila peneliti atau pengumpul data telah mengetahui dengan pasti tentang informasi apa yang akan diperoleh.

Wawancara dilakukan peneliti dengan alasan agar peneliti mampu mengajukan pertanyaan dengan bertatap muka langsung pada partisipan. Dengan penggunaan teknik wawancara, partisipan juga lebih bisa 
menyampaikan informasi secara langsung sehingga peneliti mampu mendapatkan jawaban lebih rinci dari pertanyaanpertanyaan yang diajukan peneliti kepada partisipan.

\section{Teknik Observasi}

Basrowi dan Suwandi, (2008:109) Dalam penelitian ini, peneliti tidak terlibat dan hanya sebagai pengamat independen. Selama proses observasi Peneliti mengamati pelaksanaan SOP pada anak balita dari bangun tidur jam 05.00 WIB sampai anak balita tidur pada jam 20.00 WIB dan peneliti ingin mengteahui tentang Pelaksanaan Standar Operasional Prosedur (SOP) secara keseluruhan pada anak balita dipanti Asuhan Kasih Sayang Kota Bengkulu.

\section{Teknik Dokumentasi}

Menurut Sugiyono (2006: 270) mengemukakan bahwa dokumentasi merupakan catatan peristiwa yang sudah berlaku. Dokumentasi yang didapatkan oleh peneliti selama di lapangan seperti SOP, absen nama anak balita, struktur organisasi, SK Peraturan Mentri sosial Tahun 2011 dan lampiran keputusan pengesahan pendirian yayasan dari Menteri Hukum dan Hak Asasi Manusia Republik Indonesia.

Penelitian ini pengumpulan data akan dilakukan juga secara dokumentasi baik itu dokumen tertulis, arsip, dan gambar atau foto. Dokumentasi digunakan sebagai data pendukung dan pelengkap bagi data primer yang diperoleh melalui observasi dan wawancara.

Sedangkan untuk menguji kredibilitas data, peneliti menggunakan trianggulasi.
Sugiyono (2017:273), Triangulasi diartikan sebagai pengecekkan data dari sebagai sumber dengan berbagai cara, dan berbagai waktu. Adapun macam-macam trianggulasi yaitu:

1. Triangulasi sumber

Triangulasi sumber untuk menguji kredibilitas data dilakukan dengan cara mengecek data yang telah diperoleh melalui beberapa sumber.

2. Triangulasi teknik

Triangulasi teknik untuk menguji kredibilitas data dilakukan dengan cara mengecek data kepada sumber yang sama dengan teknik yang berbeda. Misalnya data yang diperoleh dengan wawancara, lalu dicek dengan observasi, dokumentasi.

3. Triangulasi waktu

$\begin{array}{ccr}\text { Waktu } & \text { juga } & \text { sering } \\ \text { mempengaruhi } & \text { kredibilitas } & \text { data. }\end{array}$
Untuk itu dalam rangka pengujian kredibilitas data dapat dilakukan dengan cara melakukan pengecekan dengan wawancara, observasi, atau teknik lain dalam waktu atau situasi yang berbeda.

Pada penelitian ini, peneliti melakukan analisis data, berupa:

1. Reduksi data

Mereduksi data berarti merangkum, memilih hal-hal yang pokok, memfokuskan pada hal-hal yang penting, dicari tema dan polanya, dengan demikian data yang telah direduksi akan memberikan gambaran yang lebih jelas, dan 
mempermudah peneliti untuk melakukan pengumpulan data selanjutnya.

2. Penyajian data

Dalam penelitian kualitatif, penyajian data bisa dilakukan dalam bentuk uraian singkat, bagan, hubungan antar kategori, flowchart dan sejenisnya. Pada proses penyajian data ini, data yang diperoleh akan mengalami perkembangan karena fenomena sosial yang bersifat kompleks dan dinamis.

3. Kesimpulan/verifikasi

Kesimpulan awal yang dikemukakan masih bersifat sementara, dan akan berubah bila tidak ditemukan bukti-bukti yang kuat yang mendukung pada tahap pengumpulan dan berikutnya. Tetapi apabila kesimpulan yang dikemukakan pada tahap awal, didukung dengan bukti-bukti yang valid dan konsisten saat peneliti kembali kelapangan mengumpulkan data, maka kesimpulan yang dikemukakan merupakan kesimpulan yang kredibel.

\section{HASIL DAN PEMBAHASAN}

Penelitia ini berlangsung di Panti Asuhan

Kasih Sayang Kota Bengkulu yang beralamatkan di Jl. Tanggul Rt $01 \mathrm{kel}$. Bentiring kec. Muara bangkahulu. Berfokus pada pelaksanaan SOP di Panti Asuhan Kasih Sayang Kota Bengkulu meliputi asupan pada anak balita, jadwal tidur, dan jadwal ibadah.

Pada pelaksaan SOP pada anak balita, seperti asupan pada anak balita pada saat sebelum dan saat pandemi asupan yang diberikan pada anak masih seperti biasanya makan nasi denganauk telor ikan, ayam, sayuran dan satu gelas susu karena donatur masih aktif dalam membantu memberikan sembako atau pun uang.

Pelaksaan Jadwal tidur siang pada anak balita jam 13.00 WIB. Jadwal tidur malam pada anak balita jam 20.00 WIB sebelum tidur malam anak-anak makan malam bersama-sama dengan menu pariatif dan sholat isya berjamaah.

kegiatan ibadah pada anak balita di Panti Asuhan berdasarkan SOP yang sudah dibuat seperti sebelum melaksanakan sholat subuh yakni mencuci muka dan mengambil wudhu, sebelum sholat zhuhur anak diberikan waktu untuk istrahat dan nonton tv serta didampingin pengurus panti, ashar sebelum sholat ashar anak-anak mandi sore dan didampingi oleh Ibu Fera Isnata, sebelum sholat maghrib anak-anak disuruh duduk smbil menunggu azan, sholat isya sebelum sholat isya anak-anak diajak bercerita diruang sholat sambil menunggu azan. Kegiatan sholat subuh berjamaah dilakukan pada pukul $05.00 \mathrm{WIB}$, sholat zhuhur pukul 12.15 WIB, sholat ashar pukul 16.00 WIB, sholat maghrib pukul $18.30 \mathrm{WIB}$, sholat isya pukul 20.00 WIB, kegiatan ibadah ini dilaksanakan didalam ruang seperti biasanya.

Adapun hasil penelitian dari berbagai teknik pengumpulan data yaitu:

1. Wawancara

a. Asupan yang diberikan berupa nasi dengan lauk telor ikan, ayam, sayuran dan satu gelas susu karena donatur masih aktif dalam 
membantu memberikan sembako atau pun uang.

b. Jadwal tidur dilaksanakan sesuai dengan jadwal yang telah ditetapkan. Jadwal tidur siang pada anak balita dilaksanakan jam 13.00 WIB. Jadwal tidur malam pada anak balita jam 20.00 WIB sebelum tidur malam anak-anak makan malam bersama-sama dengan menu pariatif dan sholat isya berjamaah.

c. kegiatan ibadah pada anak balita berdasarkan SOP di Panti Asuhan kasih sayang Kota Bengkulu. sebelum melaksanakan sholat subuh yakni mencuci muka dan mengambil wudhu, sebelum sholat zhuhur anak diberikan waktu untuk istrahat dan nonton tv serta didampingin pengurus panti, ashar sebelum sholat ashar anak-anak mandi sore dan didampingi oleh Ibu Fera Isnata, sebelum sholat maghrib anakanak disuruh duduk smbil menunggu azan, sholat isya sebelum sholat isya anak-anak diajak bercerita diruang sholat sambil menunggu azan. Kegiatan sholat subuh berjamaah dilakukan pada pukul 05.00 WIB, sholat zhuhur pukul 12.15 WIB, sholat ashar pukul 16.00 WIB, sholat maghrib pukul 18.30 WIB, sholat isya pukul 20.00 WIB, kegiatan ibadah ini dilaksanakn didalam ruang seperti biasanya.

2. Observasi
Observasi pada hari Sabtu 30 Januari 2021 pukul 08.00 di Panti Asuhan Kasih Sayang Kota Bengkulu berupa diskusi antara pendiri panti asuhan dan Bapak Riko Tampati serta Ibu Merlin Darlia.

a. Observasi terhadap 27 Januari 2021 pukul 08.00 di kamar tidur anak balita berupa diskusi antara pendiri panti asuhan dan Fera Isnata selaku pembina/pengasuh anak balita di Panti Asuhan Kasi Sayang Kota Bengkulu. Di dapatkan hasil bahwa ada SOP pada anak balita di Panti Asuhan Kasih Sayang Kota Bengkulu.

b. Senin 9 Februari 2021 pukul 12.30 di kamar anak panti melihat anak-anak balita sholat zhuhur bersama. Di dapatkan hasil bahwa ada SOP pada anak balita di Panti Asuhan Kasih Sayang Kota Bengkulu.

3. Dokumentasi

Pada teknik dokumentasi, peneliti menemukan data berupa SOP, absen nama anak balita, struktur organisasi, SK Peraturan Mentri sosial Tahun 2011, panti asuhan dan lampiran keputusan pengesahan pendirian yayasan dari Menteri Hukum dan Hak Asasi Manusia Republik Indonesia.

\section{SIMPULAN}

Setelah dilaksanakan penelitian ini, berdasarkan data dan informasi yang diperoleh peneliti berkenaan dengan pelaksanaan Sop pada anak balita di panti 
asuhan Kasih Sayang Kota Bengkulu. Maka dapat disimpulkan bahwa:

1. Berdasarkan temuan penelitian terkait tujuan mendiskripsikan asupan pada anak balita pada jam 06.00 WIB. Asupan pada anak balita pada saat sebelum dan saat pandemi asupan yang diberikan pada anak masih seperti biasanya makan nasi dengan lauk ikan, ayam, telor sayuran dll dan di beri susu, karena donatur masih aktif dalam membantu memberikan sembako atau pun uang.

2. Pelaksanaan jadwal tidur siang pada anak balita jam 13.00 WIB. Jadwal tidur malam pada anak balita jam 20.00 WIB sebelum tidur malam anak-anak makan malam bersamasama dengan menu pariatif dan sholat isya berjamaah.

3. kegiatan ibadah pada anak balita di Panti Asuhan berdasarkan SOP yang sudah dibuat seperti sebelum melaksanakan sholat subuh yakni mencuci muka dan mengambil wudhu. Kegiatan sholat subuh berjamaah dilakukan pada pukul 05.00 WIB, sholat zhuhur pukul 12.15 WIB, sholat ashar pukul 16.00 WIB, sholat maghrib pukul 18.30 WIB, sholat isya pukul 20.00 WIB, kegiatan ibadah ini dilaksanakn didalam ruang seperti biasanya.

Melaksanakan standar operasional prosedur di Panti Asuhan Kasih Sayang Kota bengkulu semua struktur organisasi yang ada baik pendiri yayasan ketua dan pengasuh harus berkerja sama dan berkoordinasi untuk melaksanakan
SOP yang sudah dibuat dan disepakati sebagai controling pada anak balita dan salah satu SOP dilaksanakan menggunakan protokol kesehatan seperti mencuci tangan sebelum beraktifitas, memakai masker dan tetap social distencing.

Peneliti juga memberikan rekomendasi kepada peneliti selanjutnya, jika ingin melakukan penelitian selanjutnya aka melakukan penelitian lanjutan di Panti Asuhan Kasih Sayang Kota Bengkulu diharapkan dapat mengumpulkan data-data.

\section{DAFTAR PUSTAKA}

Agus Zainal, Journal Of Lifelong Learning $\mathbf{2 . 2}$ (2019). Pelatihan Tes CPNS pada LPK Corie Center.

Hartatik, Indah Puji. 2014. Buku Pintar Membuat S.O.P. Flash Book. Yogyakarta

Santrock, John W. 2017. Masa Perkembangan Anak. Salemba Humanika.

Joseof, Soelaiman (1992). Konsep Dasar Pendidikan Luar Sekolah. Jakarta: Bumi Aksara

Sugioyono. 2013. Metode Penelitian Kuantitatif, Kualitatif, dan Kombinasi. Alfabet, Bandung 